\title{
Article \\ Consumer Attitudes to the Smart Home Technologies and the Internet of Things (IoT)
}

\author{
Elena Korneeva ${ }^{1,2}$, Nina Olinder ${ }^{3,4}$ and Wadim Strielkowski ${ }^{5,6, *(D)}$ \\ 1 Department of Mass Communications and Media Business, Financial University under the Government of \\ the Russian Federation, Leningradsky Prospekt, 49, 125993 Moscow, Russia; ENKorneeva@fa.ru \\ 2 Institute of Finance, Economics and Management, Togliatti State University, Belorusskaya Str. 14, \\ 445020 Togliatti, Russia \\ 3 Department of Social Systems and Law, Samara National Research University, Moskovskoye Shosse 34, \\ 443086 Samara, Russia; olindernv@ssau.ru \\ 4 Department of Constitutional and Administrative Law, Togliatti State University, Belorusskaya Str. 14, \\ 445020 Togliatti, Russia \\ 5 Department of Agricultural and Resource Economics, University of California, Berkeley, 303 Giannini Hall, \\ Berkeley, CA 94720, USA \\ 6 Department of Trade and Finance, Faculty of Economics and Management, Czech University of Life Sciences \\ Prague, Kamýcká 129, Prague 6, 16500 Prague, Czech Republic \\ * Correspondence: strielkowski@berkeley.edu
}

check for updates

Citation: Korneeva, E.; Olinder, N.; Strielkowski, W. Consumer Attitudes to the Smart Home Technologies and the Internet of Things (IoT). Energies 2021, 14, 7913. https://doi.org/ 10.3390/en14237913

Academic Editors: Abu-Siada Ahmed and Joao Ferreira

Received: 17 October 2021

Accepted: 23 November 2021

Published: 25 November 2021

Publisher's Note: MDPI stays neutral with regard to jurisdictional claims in published maps and institutional affiliations.

Copyright: (c) 2021 by the authors. Licensee MDPI, Basel, Switzerland. This article is an open access article distributed under the terms and conditions of the Creative Commons Attribution (CC BY) license (https:// creativecommons.org/licenses/by/ $4.0 /)$.

\begin{abstract}
This paper focuses on the consumer preferences for the so-called "smart homes" (also known as "smart houses") which represent a novel addition and a product of the on-going digitalization and the deployment of the Internet of Things (IoT). The major scientific contribution of our study is the empirical model build on the data from the online questionnaire conducted with randomly selected respondents $(\mathrm{N}=523)$ from four European Union (EU) countries and Russia. Even though our results are subject to limitations (no Southern of Northern European countries are included in the scope of this research, which might have yielded different results due to the differences in wealth of citizens and climate in comparison to the Central and Eastern European countries or Germany), they demonstrate that the users included in our sample generally feel inclined to the smart homes technologies and perceive them as a plausible means for improving the safety and security of their lives. On the other hand, some respondents from our sample expressed their concerns over the cybersecurity and technology dependence issues associated with smart homes. It is also apparent that younger respondents (aged 16-35) featured in our research are more worried about their personal data being monitored and analyzed (with a pending threat of leakages). All these results are original and constitute an important scientific value-added to the field of research in smart home technologies and their acceptance by the general public. We demonstrate that the further enhancement of smart homes, and the increase of their popularity and affordability among the customers both in the Central and Eastern European countries and beyond, might depend on the development of the smart grids which these smart homes are an integral part of. The reliability of the smart systems constitutes the key element for achieving the satisfaction of the smart homes residents, and hence needs to be achieved and secured in an effective way. This would ensure the right mix and balance of energy security and efficiency for all customers involved in this process.
\end{abstract}

Keywords: smart homes; Internet of Things; consumer attitudes; smart grids; energy security

\section{Introduction}

The "smart home" (also often called "the smart house") is a living space that employs a network of interconnected devices via the Internet to remotely monitor, control, monitor, and steer a variety of aspects of a home, such as lighting, thermostat, air conditioning, heating, and ventilation [1-3]. Home automation refers to the concept in which all living aspects of the kitchen, bathroom, living room, bedroom, and other areas in a given 
household are controlled and managed by automated devices and devices connected to the Internet $[4,5]$. The concept of smart automated households where all the features would be interconnected and operated using the information and communication technologies emerged in the 20th century, but gained wide popularity only recently, with the widespread use of Internet-based technologies, and mobile devices, such as smartphones and tablets, and powerful Wi-Fi connection, as well as AI-powered voice recognition.

Even though smart homes are the product of the 4th Industrial Revolution and the digitalization and computerization of the economy, the concept was known well before our digitalized era; for example, as a means of taking care of the elderly or disabled persons [6-10].

In the 2020s, we are looking at the development of smart homes with smart appliances and smart lighting, as well as smart security systems that might include cameras, sensors, smart meters, and thermostats [11,12]. This development goes hand-in-hand with the deployment of smart surveillance cameras and voice assistants that are based on recent advances in the voice and image recognition and processing based on the artificial intelligence (AI) $[13,14]$. Some of these functions raise concerns about the privacy of consumers in smart homes, and their data leakages to the big technological giants [15-17].

It is apparent that, initially, the smart home services were encouraged to reduce manual work and make life simpler, easier, and safer. In addition, they were aimed at home automation, home security, intelligent lighting, and intelligent security systems [18-20]. Since then, the development of the wireless Internet and smartphones has expanded the idea of the smart houses that can be controlled from a distance using remote connection [21-23]. Now that the Internet of Things (IoT) has become a reality, the concept has boosted the automation and remote control that enable the monitoring and steering of the devices used in modern households [24-28]. Smart homes have developed artificial intelligence services that work on their own-and understand the behavior of their residents. These smart home systems are usually very flexible when it comes to the functions that they have at their disposal, such as lighting, heating, ventilation, air conditioning, and lighting, as well as the smart meters that ensure a two-way flow of energy and information [29-33].

Currently, there has been an increase in worldwide consumer spending in the smart home sector [34]. It is no wonder that the trend is going upwards- the recent COVID-19 pandemic has brought about a real digital surge and made more potential users familiar with smart devices, as well as making them interested in smart home technologies.

Furthermore, the term "smart house" is also used for embedded living environments [35-37]. However, the concept of a smart home has gradually expanded and incorporated the longer-standing reality of home automation with the aforementioned lighting and room controls, to name just a few. More importantly, smart homes are not only IoT-enabled, but so are an array of smart devices, lighting, and other household appliances [38-40]. The beginning of home automation goes back to the early 1990s, with video entertainment, surveillance, and security [41,42]. In addition, there is smart speaker technology, which is particularly popular in the United States, with $31 \%$ of households using smart speakers such as Amazon Echo and Google Nest [43]. Thermostats, lighting, and other appliances can be controlled via smartphones or tablets. By connecting to a portable device, users can receive notifications and updates about problems in their homes.

Smart home devices can be controlled from any device in the home, such as a smartphone, tablet, or computer, and can connect to each other via Bluetooth, $\mathrm{Wi}-\mathrm{Fi}$, Bluetooth 4.0 , or other wireless networks [44,45]. Intelligent thermostats, air conditioning, lighting, and other household appliances can be controlled from one home automation system and checked from another. Those are controlled via apps from a smartphone or a tablet, and the user can make certain changes that take effect in real time, such as changing the temperature of a thermostat or lighting in a room [46].

However, all of the above comes at a cost. In order to create a smart house, one has to replace the old equipment and add a range of devices, while discovering new technologies that accompany the indoor and outdoor spaces. The seamless integration of these new 
arrivals will make the homeowner's job much easier and allow her or him to keep switching to the latest lifestyle technologies.

Nevertheless, security in the home can skyrocket if one integrates security and monitoring functions into the smart home network [47]. These technologies allow homeowners to operate, manage, and monitor their homes from their smartphones. With automation, one can control all of the devices in the smart home from anywhere at the touch of a button. This might help to ensure that lights and appliances are turned on when the person is not at home, saving electricity and reducing the bill. However, the security might be very expensive, and many users are reluctant to observe the precautions and follow the measures to minimize their risks. In this case, they might become an easy target for burglars or hackers who are proficient in the new technologies, and can easily break into smart homes to steal both the property or the sensitive data [48].

This paper is structured as follows: Section 2 discusses the role and the place of the smart homes in the system of smart grids. Section 3 presents the obstacles for deploying smart home technologies. Section 4 draws a concise and comprehensive SWOT analysis of the new opportunities, as well as obstacles for the development of the smart homes market. Section 5 provides the research methodology and data description. Section 6 outlines the results of the empirical model results and discussions of these results. Finally, Section 7 concludes the paper by outlaying the final results and outcomes, as well as providing some useful policy implications.

\section{Smart Homes and Smart Grids}

Recently, smart houses are being discussed as a part of smart grids. One of the main components of smart grids is the use of digital technologies and advanced applications for energy management. Smart grid technology is deemed to make local power generation systems more feasible $[49,50]$. Even though there might be some safety and security issues associated with this power generation, the potential benefits that it can bring outweigh the harms and would also mean that the smart grid technologies would have a smoother way into the future. Smart grids combine the current electric grids and the information and communication technology for the creation of cost-effective and efficient ways to distribute energy. The main function of a smart grid is to control power consumption while offering the network more flexibility in the event of an emergency. It is expected that the two-way communication used in a smart grid will enable dynamic monitoring of the electricity consumption and open up the possibility of the automated planning of its use [51,52].

Hence, the position of the smart home within the smart grid represents a household equipped the smart meters, renewable energy generation and storage, as well as the electric vehicle (EV), which are connected to the wider system ranging from the energy generation and transmission to a whole network of other smart homes and smart cities.

It is therefore imperative for the intelligent grid mechanisms to take into account the related challenges, such as energy efficiency, energy security and the availability of renewable energy sources [53,54]. A key component that distinguishes an intelligent grid from the traditional grid is its ability to coordinate and integrate various sources of renewable energy $[55,56]$. Typically, this embeds the whole electricity system from the generation of electricity to its transmission and distribution, as well as storage. A smart grid is constructed to integrate all parts of the system in a way that minimizes the costs and environmental impact, while maximizing the system reliability, resilience and stability [57]. An advanced metering infrastructure includes an improved tax collection, energy storage and intelligent monitoring, as well as the control systems for any smart home. A smart grid is actually a system of smart homes, smart energy storage and smart grids that provides the most advanced monitoring and control of the electricity grid in the world. It consists of the sensor, communication, control and actuation systems that enable comprehensive monitoring, control and power supply to the grid. These features allow the utility to accurately predict, monitor, track, record and control the flow of electricity into and out of the grid, as well as to control the flow of energy from one's home to the utility. By 
converting the grid into a decentralized electricity generation system, it can be transformed into a bi-directional electricity system, wherein the customer can supply the grid with all his or her energy needs and the needs of the utility [58].

Therefore, a smart grid with its coordinated electricity grids will have a huge impact on the grid's performance. It allows us to facilitate the ability to automatically regulate household electricity use and respond to price signals from the supplier, as well as to respond automatically to demand for electricity and the supply of electricity from other sources, such as wind and sun. Powerline communication (PLC) is a standard for communication between a power line and an external power grid, as defined in the IEEE 802.15.4 standard. Zigbee is the most popular wireless communication protocol for power lines based on the IEEE802 standard and is defined as high speed, low cost and high bandwidth multi-channel communications [59].

Smart measurement systems can be used for the grid computing to optimize energy consumption in data centers. They introduce a new architecture that integrates smart grids into conventional grids-computer systems wherein different meters in a data center can provide information on the energy consumption of the power grid and the use of power lines. This hierarchical architecture includes a number of interfaces that can work together to avoid power outages and reduce energy consumption at peak times.

There are tools such as the integrated storage software that allow homeowners and businesses with on-site panels to automatically switch to their own stored electricity, based on current load and other factors. In general terms, rebalancing the energy mix of a smart city is a major challenge for the future of renewable energy worldwide [60]. Smart cities projects are exploring how to promote more renewable grids, and smart grids will help to keep distribution systems up to date. In buildings, shadow counters and usage information stands are installed, as well as solar panels on the rooves. The focus on decentralized electricity generation has increased in recent years, as it can meet the electricity demand in remote and rural areas where no main electricity network exists or is unreliable. Different types of decentralized energy resources can be effectively coordinated through local energy management. In this context, a micro-grid refers to a controlled system of load groups from decentralized micro energy sources that can supply themselves with electrical energy.

The smart home devices that are now widely available on the market and that represent the best ones for controlling and communicating with one's household according to the recommendations of the technology analysts and professionals are numerous [61,62]. However, the following nine smart home devices: smartphones, smart TV, voice assistant, smart lights, motion detectors, monitoring cameras, smart thermostat, smart watering, and smart shutters/blinds appear to be the most widely known and highly recommended. We have decided to focus on them in our empirical model, and the analysis that will be presented in Section 5 of this paper.

\section{Obstacles to Deploying Smart Home Technologies}

Recently, smart home trends have included cloud-driven smart home systems, smart technology that matches consumer decor, and automated door closing systems. Other drivers are the falling costs, higher energy costs due to higher government regulations on energy consumption, and the increased awareness and concern for the environment among consumers. As the integration of smart features into the home becomes more attractive, companies that manufacture traditional household appliances are trying to create the products that follow these trends. Many competing manufacturers are developing different smart home systems and technologies, and we are seeing the development of new products, such as smart thermostats, smart door locks, and security systems. Connecting and linking different systems, ranging from the lack of integration of smart devices to the need for an integrated security system, constitutes an array of issues [63]. In addition, designers and users must take into account how the performance dynamics between man and machine change; for example, through the use of intelligent thermostats and intelligent door locks. The need for these considerations is illustrated by the fact that many smart home devices 
control humans and that they are used in environments that are different from those already introduced.

For decades, the promise of a "smart home" has seduced companies that want to capitalize on the dynamics of connected home technologies by predicting and controlling residents' desires without any human interaction. With the introduction of smart thermostats and smart door locks, we may be closer than ever to realizing this dream. Experts predict that a truly connected smart home, where devices can talk to each other, will be decades away, but to some extent, the "smart home" is already there. There are a number of challenges to be addressed, from data security and interoperability between devices, to data protection, data security, and data storage [64]. The issue is not setting up the connection of a few devices, but solving real problems and creating real value. At best, smart homes can solve problems, create new efficiencies, and even save money. IoT is set up in order to create real value for users, but it has yet to enter a smart home that can achieve the goal of making it for all users. The drivers supporting the growth of the smart home market are largely based on a growing sense of security. Growing consumer awareness of the safety issues, such as home security, is pushing consumers to integrate smart security and surveillance devices into their homes. Demand for smart devices is trending upwards, with the growth of the global smart home market and a growing number of smart homes in some large countries such as China and India, as well as the United States [65]. The fast-growing market segment in these countries is in terms of the product protocols and standards.

Nevertheless, the high costs of smart devices, as well as various technological issues, such as interconnectivity or charging standards, might also slow down the growth of the global smart home market. The growth of wired and wireless communications technologies is driving the adoption of smart home technologies, such as smart lights, smart thermostats and smart devices, and creating the potential for some new smart home applications. The smart home market is used to control smart home systems to provide homeowners with the security, convenience, and energy efficiency.

Moreover, the smart home market has changed significantly in recent years as far as the smart home technologies have evolved from low data rates and low frequencies to high data rates and high frequencies. The adoption of smart home technologies has been lower than expected, although applications such as automated security, voice-controlled thermostats and smart lights have been very popular, and their sales have been growing each year (especially in recent years, when the COVID-19 pandemic has shown the importance of the digital technologies for global communication, work, and education).

\section{SWOT Analysis for the Development of Smart Homes Market}

Smart homes surely have huge potential in the world market. It is quite clear that the global market will grow at a relatively high rate in the years to come. Industry experts predict that the smart home security system market will have an estimated market value of USD 1.2 billion by the end of 2020, compared to USD 0.5 billion in 2015 [66].

The latest developments and activities include a detailed analysis of the smart home security systems market in the global market, and its market shares, growth rates and competitive conditions. The profile of the main players will be covered, and a detailed analysis of each company will be included. The industry's key players and their latest news, their key strategies, including their product and business portfolios, and an overview of emerging players, such as Amazon, Apple, Google, Microsoft, Cisco, Intel, HP, IBM, Samsung, Huawei, Lenovo, Nest, Symantec, Philips, Schlumberger, Siemens, Telenor, BAE Systems, Honeywell, EMC, Panasonic, and others, as well as the latest developments in their product and business portfolios, are important. The industry is a key driver for smart home growth in North America, Europe, Asia-Pacific and Latin America. The main players are being followed through recent acquisitions, mergers and research in the industry, and major product developments are being shown. In addition, a detailed analysis of the market share and growth rate of the key companies in this sector will be carried out. China, a leading producer of a wide range of household appliances, is forecast to be the leading 
market for the smart appliances over the forecast period. As the price of these products is currently higher than that of the conventional non-smart devices, and as more and more device manufacturers are challenging themselves to incorporate these features, the market will also have economical products in the near future.

Table 1 reports the results of the SWOT analysis for the smart homes market in the years to come. As with all SWOT tables, it is divided into four sections presenting the strengths, weaknesses, opportunities, as well as threats to the smart home industry.

Table 1. SWOT analysis for the smart homes market.

\begin{tabular}{|c|c|}
\hline Strengths & Weaknesses \\
\hline $\begin{array}{ll}\text { - } & \text { Coordination between different } \\
\text { devices and appliances } \\
\text { - } \quad \text { Simple user interface } \\
\text { - } \quad \text { Single protocols } \\
\text { - } \quad \text { Customer relations }\end{array}$ & $\begin{array}{l}\text { - } \quad \text { Costs of system integration and recurring fees } \\
\text { - } \quad \text { Replacement issues } \\
\text { Product appearance and aesthetics }\end{array}$ \\
\hline Opportunities & Threats \\
\hline $\begin{array}{l}\text { - } \quad \text { Platform integration } \\
\text { - } \quad \text { the business models drawing from } \\
\text { - Increasing the use of mobile devices } \\
\text { - } \quad \text { Integration and bundling }\end{array}$ & $\begin{array}{ll}\text { - } & \text { Open-source products and developers } \\
\text { - } & \text { Peer-to-peer (P2P) trading and communication } \\
\text { - } & \text { Product differentiation } \\
\text { - } & \text { Open APIs }\end{array}$ \\
\hline
\end{tabular}

One can see that among the strengths are the coordination of many different devices and appliances, simple user interface, and single protocols used by the users, as well as functioning customer relations. On the other hand, the weaknesses include the costs of system integration and recurring fees as well as replacement issues. Many smart home technologies are quite new, and some technical issue might always emerge, and then they would need to be solved promptly. A very important factor that attracts consumer attention is the product appearance and aesthetics, which means the presentation of the product, its design, wrapping, and other presentability issues. It is a well-known fact that many consumers base their preferences on the design of technological products (e.g., Apple or Google).

As for the opportunities, we can distinguish such factors as the platform integration, new business models drawn from the principles of sharing economy, increasing use of mobile devices from which smart homes are typically operated now, as well as integration and bundling. The threats include the open-source products and developers that might create competition offering the same products at lower or zero costs, P2P trading and communication, and product differentiation, as well as the open APIs (see Table 1).

With the introduction of smart homes and awareness of the new functions of these technologies, device manufacturers are shifting their focus to the smart appliance segment. The market will also see an increased demand from developing regions, mainly due to the readily available advanced products in these regions. Critical insight into smart the homes systems should be done by segmenting the market by product type, application, and region. One can see that companies that may emerge after the unprecedented outbreak of COVID-19 and the key players in the smart homes market.

Competitive analysis of the key players should be a key focus of the different forecasts associated with the smart home market, such as market share, market size, growth rate, trends, opportunities, challenges and opportunities for key players in the smart home market. Therefore, based on the analysis presented in Table 1, we would focus our study on the demand for the smart home technology by the product, used technology, end-user, and region. Moreover, we would assess the trends and developments in the social acceptance of the smart homes as the key factors influencing the growth of the assisted housing market and the driving and braking forces behind it. In order to do so, we would concentrate 
on the nine most commonly used and widely available smart home devices that were described in Section 2. All of these would represent the factors that would most likely influence the global market growth and future prospects for the smart home market and the Internet of Things, as well as for the future users' preferences for these technologies.

\section{Data and Research Methodology}

The empirical model that is presented in this section of our paper was designed to assess the consumer attitudes to the smart home technologies and the Internet of Things. The model employs the data collected from the respondents in five different countries inside and outside the European Union (EU).

We collected our data from the online survey conducted with the randomly selected respondents $(\mathrm{N}=523)$ in four EU countries and the Russian Federation. The empirical data for our model were collected using our representative online survey (via a popular surveying tool SurveyMonkey) which was carried out from May 2019 to March 2020 in four EU countries (represented by the Czech Republic, Germany, Poland, and Slovakia), as well as in the Russian Federation. The respondents were approached using an online interface via our own contact points (the so-called "gatekeepers") in the countries involved in this research project. The selection of the respondents and the reliability of local gatekeepers became possible using the extensive graduate student networks in the countries covered by our research. The graduate students recruited in their respective countries were taught how to administer online questionnaires and deal with eventual difficulties and arising issues. In order to ensure the ethical norms and standards that are typical for this type of surveys, written informed consents were obtained from all the subjects prior to the study via the simple online form which was a part of the questionnaire survey.

In order to make the sample more representative, the quotas were set for such characteristics as age, gender, and the country of residence. Overall, after the data were cleared from the outliers and missing values, the final sample used for our analysis included 523 valid observations. The average age of respondents was 42 years. In total, $54 \%$ of the respondents were male, and $46 \%$ were female. More than $80 \%$ of respondents had a college degree. Of all respondents, 32\% had a higher education degree (university degree or higher). Table 2 reports the statistics of the respondents, as well as the numbers of households per each country.

Table 2. Statistics of the respondents.

\begin{tabular}{ccc}
\hline \multirow{3}{*}{ Age } & $18-24$ years & $22 \%$ \\
& $25-35$ years & $30 \%$ \\
& $36-55$ years & $43 \%$ \\
Gender & $56-80$ years & $5 \%$ \\
\hline \multirow{2}{*}{ Level of education } & Female & $46 \%$ \\
& Male & $54 \%$ \\
\hline \multirow{3}{*}{ Number of households } & Unfinished primary & $12 \%$ \\
& Primary education & $56 \%$ \\
& University degree or higher & $32 \%$ \\
\hline & Czechia & 86 \\
& Germany & 133 \\
& Poland & 102 \\
& Slovakia & 50 \\
\hline
\end{tabular}

Source: Own results.

In addition, Table 3 which follows, shows the respondents' attitudes and familiarity with the smart homes divided by their countries of origin. 
Table 3. Respondents' attitudes and familiarity with smart homes by countries.

\begin{tabular}{|c|c|c|c|c|c|}
\hline \multirow[b]{2}{*}{ Familiarity with Smart Homes } & \multicolumn{5}{|c|}{ Country } \\
\hline & $\begin{array}{c}\text { Czechia } \\
N=86\end{array}$ & $\begin{array}{c}\text { Germany } \\
N=133\end{array}$ & $\begin{array}{l}\text { Poland } \\
N=102\end{array}$ & $\begin{array}{c}\text { Slovakia } \\
\mathrm{N}=\mathbf{5 0}\end{array}$ & $\begin{array}{c}\text { Russia } \\
N=152\end{array}$ \\
\hline Familiar & $58 \%$ & $75 \%$ & $62 \%$ & $53 \%$ & $44 \%$ \\
\hline Unfamiliar & $12 \%$ & $14 \%$ & $18 \%$ & $14 \%$ & $29 \%$ \\
\hline Do not know & $30 \%$ & $11 \%$ & $20 \%$ & $33 \%$ & $27 \%$ \\
\hline \multicolumn{6}{|c|}{ Smart home devices } \\
\hline Smartphone & $90 \%$ & $96 \%$ & $95 \%$ & $89 \%$ & $95 \%$ \\
\hline Smart TV & $54 \%$ & $58 \%$ & $55 \%$ & $50 \%$ & $32 \%$ \\
\hline Voice Assistant & $45 \%$ & $51 \%$ & $48 \%$ & $40 \%$ & $25 \%$ \\
\hline Smart lights & $34 \%$ & $46 \%$ & $41 \%$ & $29 \%$ & $13 \%$ \\
\hline Motion detectors & $30 \%$ & $38 \%$ & $34 \%$ & $23 \%$ & $10 \%$ \\
\hline Monitoring cameras & $21 \%$ & $26 \%$ & $24 \%$ & $17 \%$ & $48 \%$ \\
\hline Smart thermostat & $13 \%$ & $24 \%$ & $16 \%$ & $12 \%$ & $11 \%$ \\
\hline Smart watering & $15 \%$ & $21 \%$ & $20 \%$ & $8 \%$ & $6 \%$ \\
\hline Smart shutters/blinds & $11 \%$ & $19 \%$ & $17 \%$ & $10 \%$ & $4 \%$ \\
\hline
\end{tabular}

Source: Own results.

It becomes quite apparent from Table 2 that both the familiarity with the smart homes as a concept and various smart technologies associated with smart homes differs from country to country. From our results, it appears that the most technologically advanced users who are also quite familiar with the concept of smart homes and who use many smart home appliances in their daily routines originated from Germany. They are followed by their counterparts from Poland, the Czech Republic, and Slovakia. Russian users appear to be less familiar with smart homes, even though they tend to use some smart home-related devices, such as smartphones and monitoring cameras (those are well-known in Russia and ubiquitous in vehicles for recording possible traffic accidents for further evidence that can be used in courts). These findings are in accordance with the similar results obtained in the course of analogical research devoted to the adoption of novel technologies in different countries $[67,68]$.

In order to assess the attitudes towards smart homes and smart home technologies, we employ a three-stage hierarchical multiple linear regression. A hierarchical linear regression constitutes a specific type of a multiple linear regression analysis. However, in this form, additional variables are added by the researchers to the model in several consecutive steps. Typically, this is done in order to statistically control for certain variables or to see if by adding an additional variable which might significantly improve a model's ability to predict the criterion variable. In many cases, it is also done to investigate a moderating effect of a variable $[69,70]$. The model can be presented in the following way (see Equations (1)-(3) that follow):

$$
Y_{i j}=\beta_{0 j}+\beta_{1 j} X_{1 i j}+\beta_{2 j} X_{2 i j}+\ldots+\beta_{n j} X_{n i j}+\varepsilon_{i j}
$$

where:

$Y$-is a dependent variable that shows the acceptance of smart home technology of the respondent $i$ in case of the technology $j$;

$\beta$-an intercept;

$X_{1 i j}, \ldots, X_{n i j}$-dichotomous predictors in the model;

$\varepsilon_{i j}$ - the random error term.

The level-2 model can be formulated as the following:

$$
\begin{aligned}
& \beta_{0 j}=\gamma_{00}+\gamma_{01} W_{1 j}+\gamma_{02} W_{2 j}+u_{0 j} \\
& \beta_{1 j}=\gamma_{10}+\gamma_{11} W_{1 j}+\gamma_{12} W_{2 j}+u_{1 j}
\end{aligned}
$$


where:

$u_{0 j}, \ldots, u_{1 j}$-random effects;

$W_{1 j}$ and $W_{2 j}$-grand-mean centered and uncentred respectively

The model specified in Equations (1)-(3) is similar to the ones used in other related research projects focused on eliciting the users' or consumers' attitudes towards novel and smart technologies in other countries and regions (see e.g., [71-74]).

\section{Model Results and Discussions}

The section that follows here is envisaged to report and discuss the results of our empirical model which has been presented and defined in the previous section (see Equations (1)-(3)).

Table 4 that follows reports the results of three-stage hierarchical multiple linear regression, predicting the attitudes towards smart homes and smart home technologies.

Table 4. Regression results for the model predicting the attitudes towards smart homes and smart home technologies.

\begin{tabular}{|c|c|c|c|c|c|c|}
\hline \multirow[b]{2}{*}{ Variable } & \multicolumn{2}{|c|}{ Stage 1} & \multicolumn{2}{|c|}{ Stage 2} & \multicolumn{2}{|c|}{ Stage 3} \\
\hline & $\mathrm{B}(\mathrm{SE})$ & Beta & $\mathrm{B}(\mathrm{SE})$ & Beta & $\mathrm{B}(\mathrm{SE})$ & Beta \\
\hline Gender & $-0.052(0.09)$ & -0.03 & $0.093(0.087)$ & 0.056 & $0.247(0.043)$ & 0.086 \\
\hline Age & $0.105(0.003)$ & -0.107 & $-0.103(103) * *$ & $-0.139 * *$ & $-0.101(0.103) * *$ & $-0.189 * *$ \\
\hline Income & $0.329(0.046) * *$ & $0.374 * *$ & $0.305(0.054) *$ & $0.353 *$ & $0.090(0.043) * *$ & $0.206 * *$ \\
\hline Education & $0.057(0.203)$ & 0.76 & $0.0056(0.101)$ & 0.003 & $-0.074(0.076)$ & -0.039 \\
\hline Home size & $0.262(0.095)$ & 0.94 & $0.255(0.089)$ & 0.081 & $0.038(0.064)$ & 0.026 \\
\hline Openness to SH & & & $0.646(0.083) * *$ & $0.401 * *$ & $0.250(0.062) * *$ & $0.097 * *$ \\
\hline SH devices & & & $0.0365(0.055)$ & 0.035 & $0.027(0.040)$ & 0.026 \\
\hline Trust in $\mathrm{SH}$ & & & $0.104(0.029) * *$ & $0.325^{* *}$ & $0.027(0.024)$ & 0.040 \\
\hline Familiarity with $\mathrm{SH}$ & & & & & $-0.551(0.065) * *$ & $-0.236^{* *}$ \\
\hline Personal security & & & & & $-0.022(0.032)$ & -0.025 \\
\hline Positive attitude to $\mathrm{SH}$ & & & & & $0.804(0.051) * *$ & $0.684 * *$ \\
\hline Negative attitude to $\mathrm{SH}$ & & & & & $-0.426(0.045) * *$ & $-0.391 * *$ \\
\hline \multirow[t]{2}{*}{ Constant } & $4.52(0.42) * *$ & $887(0.601)$ & & & $0.207(0.585)^{* *}$ & \\
\hline & \multicolumn{2}{|c|}{$\mathrm{R}^{2}=0.058 * *$} & \multicolumn{2}{|c|}{$\mathrm{R}^{2}=0.264^{* * *}$} & \multicolumn{2}{|c|}{$\mathrm{R}^{2}=0.565^{* * *}$} \\
\hline
\end{tabular}

Source: Own results. Note: ${ }^{* *}$ Significant at the 0.01 level; ${ }^{* *}$ Significant at the 0.05 level; ${ }^{*}$ Significant at the 0.1 level.

Overall, the results stemming from our empirical models show that all the users involved in our research generally feel inclined to the smart homes technologies and perceive them as a plausible means for improving the safety and security of their lives. On the other hand, some respondents expressed concerns over the cybersecurity and technology dependence issues associated with the smart homes. This is comparable with the results obtained from the other studies [75-77]. The gender factor did not come through as significant in adapting to the smart home technologies. The income turned out to be an important factor in accepting the smart homes, probably because most of them still embed quite luxurious goods and items that are not affordable for the majority of the population which is living on the basic income.

It is also apparent that younger respondents (below 35 years) are more worried about their personal data being monitored and analyzed (with a pending threat of their personal data and sensitive information leakages, either by the hackers or due to the negligence).

Therefore, our research draws from a series of recent studies on smart home technologies, and argues that several factors influence users' perceptions and adoption decisions. In general, users agree that smart home technology can improve the quality of life in a greater degree and increase the security of residents. Smart homes and the Internet of Things are becoming increasingly popular as more households use Internet-enabled devices to monitor the user activity. All these results can help us to understand the reactions and attitudes of the consumers towards smart home device and the surveys such as the one we carried out and presented in this paper can be of a great help. Moreover, it might help us to understand not only whether some users would be willing to accept the smart home technologies and use them in the future, but also whether they would be inclined to recommend them to others and promote them among their contacts. It is also important to 
understand the environment the smart home technologies are used and how they are integrated into the traditional form of human dwellings. All of the above is a prerequisite for the success of smart homes and would largely presuppose their future, since the ambition of the smart home technologies is that the users would use them in their everyday lives on every day and every hour for performing all mundane tasks around their households.

Thanks to the availability of fast Internet connection and the development of the new technologies like the 5G Internet the smart home concept has expanded recently beyond the installation of the smart lights or smart meters to the more advanced options like the voice assistants that can communicate with the users through the speech recognition algorithms powered by the $\mathrm{AI}$ and manage their smart homes remotely. In addition, the autonomic power systems also emerge that can independently take care of the house appliances and coordinate their work.

With all that, it is important to understand which aspects are perceived by the users as important and which are not. In addition, it is important to understand whether the users feel secure and confident about using the smart home technologies and what issues they might fear.

Therefore, our paper presents a new and interesting type of study focused on the acceptance of the smart homes and the smart home technologies, and covering an interesting sample of countries. We attempted to identify the factors that play the key role in the acceptance of smart homes when viewed from the perspective of the relationship between importance and consumer confidence. In addition, our research also aimed at examining the awareness of potential smart home buyers, especially young millennials. It might be interesting to find out what the younger people know about the concept of a smart home, what constitutes the perception of factors that influence them to buy smart home technologies, and what the key features that they take into account when purchasing a smart home are. However, we would leave it to some further research that might be conducted in the nearest future given the availability of the suitable data.

\section{Conclusions}

All in all, in spite of the fact that in the 21st century smart homes are becoming more ubiquitous, and the users are becoming more familiar with them, there are still many barriers and obstacles to their widespread use that need to be better studied and comprehended by the researchers. Smart home companies in the areas of consumer electronics, home automation, health and wellness can accelerate the rise of this young, high-potential industry that is a part of the novel and popular concept of the Internet of Things, however there are many issues that need to be resolved. Some of these issues concern the technical aspects such as the wide range of producers and various lines of devices with different charging systems, frequencies, or ways to communicate with each other or with the grid. Other issues are mainly about the willingness to accept the smart home technologies and solutions by the wider population. It seems that both the Internet of Things and the smart homes need some more time to gain the full acceptance of the consumers and to persuade them that these technologies are safe and reliable. Therefore, it is very important to study the consumers' attitudes and demand for the smart homes, with a focus on various characteristics and a purpose to fully understand these attitudes and demands. This has become the major scientific value-added of our paper that combined the theoretical and methodological approach with the empirical study focusing on this important issue.

In order to tackle the issues described above, and focusing on the user-centered perspective, we developed a questionnaire survey with the purpose to study consumers attitudes towards smart home technology. Our results, obtained from five countries including the four EU countries and Russia, reveal certain concerns that are expressed by the respondents when it comes to the ease of use of the devices, the lack of a human response, and the need for training specifically for older learners. Surely, the limitations of our approach should be acknowledged, since the households featured in our sample 
come from countries that are not quite representative, for example, of the EU as such, as far as they are located in the Central and Eastern Europe with only Germany belonging to the continental area and no Southern European country or a part of Scandinavia involved. Therefore, there might be some particular socio-economic conditions and location specifics that might channel users' preferences for smart home technologies, and hence might have had an impact on our survey and its results. Preferences for the smart home technologies might differ in some parts of the world due to such factors as the wealth of the citizens and/or the climate conditions. Nevertheless, we think that the results we managed to obtain are quite interesting and represent a useful and insightful snapshot of the demand and attitudes for the smart homes in a group of European countries and Russia. These results show that the preferences for the smart home technologies are quite uniform and similar, and exhibit closer trends than one would have possibly expected or envisaged. With all that, we believe that our results constitute a major scientific contribution into the field of research embedding preferences and acceptance of the smart home technologies.

Consumers are expected to ease their way into the smart home solutions by jumping on existing hardware, such as smart lights, smart shutters, thermostats, and other smart devices. In addition, another important message stemming from our research is that the risks that smart home technology can pose should also be better presented and explained to the consumers. Hacking, eavesdropping, stealing sensitive and private data, or blackmailing might become a part of the new smart home ecosystem. In addition, it also appears both from our results, and from many similar studies that we made an overview of, that the integration to the smart energy grids and the communication between the smart devices produced by a plethora of companies, each using different standards, voltage, charges, etc., might make the situation more complicated. It is apparent now that the smart home technologies are in the works for the future that is now, but the policymakers can play a significant role in accelerating adoption and reducing their perceived risks. Measures need to be developed for harnessing the large technological giants and preventing them from selling users' personal data (for example, to the advertising agencies) with the purpose of making profits. Laws need to be implemented to protect personal information, such as the "right to be forgotten" that applies to people who want their digital footprint to be removed from the search engines or from websites.

Last but not least, our results can be used to improve the communication between the technological companies, policymakers and the potential smart home users, as well as to enhance the smart homes market, emphasizing such aspects as security, energy efficiency, or energy saving.

\section{Policy Implications}

When it comes to the implications of our study on the energy efficiency of buildings and on the indoor comfort, it is apparent that many of the same smart technologies that are used in smart homes can also be used in smart buildings, including light, energy, heating, air conditioning, security and access systems. Smart buildings can, for example, reduce the energy costs by using sensors to determine how many occupants are in a room. Most building IoT sensors use very little energy compared to the energy usage of the devices they control. Cost-effective comfort and convenience are therefore very important. Using a network of positioning and motion sensors, a smart home can control temperature and light to accommodate the rooms in the home that are all used at all times. The smart home network can include actuators that control the home's power and water supply, alert the homeowner, and control the water system's power supply, by connecting the water heaters and leak detectors that sound the alarm when a tank fails. Various systems and technologies of the Internet of Things (IoT) can be developed to increase the energy efficiency of residential and commercial buildings. Controlling devices related to building energy can lead to the significant energy savings, as IoT systems are better able to respond to the data that they collect. In the home, IoT automation and wireless sensor networks are key to reducing energy consumption. 
Furthermore, connectivity systems such as HVAC (heating, ventilation and air conditioning) and energy efficiency systems can also provide the foundations for other sensor systems. Smart homes are a new trend that is having a major impact on how technology is changing the HVAC industry. Today, intelligent technologies make indoor comfort and many other aspects of the operation of one's home more convenient. The communication technology board installed securely in the inside unit of an energy-efficient heating and cooling system uses the performance data of the HVAC system to make adjustments to reduce energy consumption for the heating and cooling of smart homes. Thermostats, which work with most traditional HVAC systems, optimize the entire house for comfort through improved cooling and dehumidification. In general terms, the idea of a smart home serves the efficient use of the energy optimization and ventilation technologies, which are interconnected in new ways to build low-energy or energy-passive houses.

Speaking about the pathways for further research, we can mention two interesting opportunities: (i) it would be very interesting to measure the willingness-to-pay (WTP) for the smart home devices that are not yet on the market. Knowing what the users would potentially want in their smart homes or what appliances would make them happier might be quite informative; (ii) it might be quite interesting to assess the consumer and user attitudes to the smart home technologies in the countries that differ in their level of life and economic development. For example, comparing the smart home technologies in Europe and Africa or Asia might provide some novel insights into this area of research, and would also create new ideas about the promotion and adoption of new technologies for the policymakers and the stakeholders in various parts of the world.

Author Contributions: Conceptualization, E.K., N.O. and W.S.; Methodology, E.K., N.O. and W.S.; Formal Analysis, E.K. and W.S.; Resources, E.K. and N.O.; Data Curation, E.K. and N.O.; WritingOriginal Draft Preparation, E.K., N.O. and W.S.; Writing-Review and Editing, E.K., N.O. and W.S.; Visualization, W.S. All authors have read and agreed to the published version of the manuscript.

Funding: This research received no external funding.

Institutional Review Board Statement: Not applicable.

Informed Consent Statement: Not applicable.

Data Availability Statement: Data available from the authors upon request.

Conflicts of Interest: The authors declare no conflict of interest.

\section{References}

1. Mocrii, D.; Chen, Y.; Musilek, P. IoT-based smart homes: A review of system architecture, software, communications, privacy and security. Internet Things 2018, 1, 81-98. [CrossRef]

2. Strielkowski, W.; Streimikiene, D.; Fomina, A.; Semenova, E. Internet of energy (IoE) and high-renewables electricity system market design. Energies 2019, 12, 4790. [CrossRef]

3. Almusaylim, Z.A.; Zaman, N. A review on smart home present state and challenges: Linked to context-awareness internet of things (IoT). Wirel. Netw. 2019, 25, 3193-3204. [CrossRef]

4. Reyes-Campos, J.; Alor-Hernández, G.; Machorro-Cano, I.; Olmedo-Aguirre, J.O.; Sánchez-Cervantes, J.L.; Rodríguez-Mazahua, L. Discovery of resident behavior patterns using machine learning techniques and IoT paradigm. Mathematics $2021,9,219$. [CrossRef]

5. Buzzi, M.; Leporini, B.; Meattini, C. Design guidelines forweb interfaces of home automation systems accessible via screen reader. J. Web Eng. 2019, 18, 477-512. [CrossRef]

6. Kamel, E.; Memari, A.M. State-of-the-Art review of energy smart homes. J. Archit. Eng. 2019, 25, 03118001. [CrossRef]

7. Yang, G.; Yang, J.; Sheng, W.; Junior, F.E.F.; Li, S. Convolutional neural network-based embarrassing situation detection under camera for social robot in smart homes. Sensors 2018, 18, 1530. [CrossRef]

8. Mshali, H.; Lemlouma, T.; Moloney, M.; Magoni, D. A survey on health monitoring systems for health smart homes. Int. J. Ind. Ergon. 2018, 66, 26-56. [CrossRef]

9. Mtshali, P.; Khubisa, F. A smart home appliance control system for physically disabled people. In Proceedings of the 2019 Conference on Information Communications Technology and Society (ICTAS), Durban, South Africa, 6-8 March 2019; pp. 1-5. [CrossRef] 
10. Pal, D.; Funilkul, S.; Vanijja, V.; Papasratorn, B. Analyzing the elderly users' adoption of smart-home services. IEEE Access 2018, 6, 51238-51252. [CrossRef]

11. Del Rio, D.D.F.; Sovacool, B.K.; Bergman, N.; Makuch, K.E. Critically reviewing smart home technology applications and business models in Europe. Energy Policy 2020, 144, 111631. [CrossRef]

12. Schieweck, A.; Uhde, E.; Salthammer, T.; Salthammer, L.C.; Morawska, L.; Mazaheri, M.; Kumar, P. Smart homes and the control of indoor air quality. Renew. Sustain. Energy Rev. 2018, 94, 705-718. [CrossRef]

13. Guo, X.; Shen, Z.; Zhang, Y.; Wu, T. Review on the application of artificial intelligence in smart homes. Smart Cities 2019, 2, 402-420. [CrossRef]

14. Khan, W.M.; Zualkernan, I.A. Sensepods: A zigbee-based tangible smart home interface. IEEE Trans. Consum. Electron. 2018, 64, 145-152. [CrossRef]

15. Dong, B.; Shi, Q.; Yang, Y.; Wen, F.; Zhang, Z.; Lee, C. Technology evolution from self-powered sensors to AIoT enabled smart homes. Nano Energy 2021, 79, 105414. [CrossRef]

16. Strielkowski, W. Social Impacts of Smart Grids: The Future of Smart Grids and Energy Market Design; Elsevier: London, UK, 2019.

17. Sadowski, J.; Strengers, Y.; Kennedy, J. More work for Big Mother: Revaluing care and control in smart homes. Environ. Plan. A Econ. Space 2021, 0308518X211022366. [CrossRef]

18. Ramadan, Z.; Farah, M.F.; El Essrawi, L. From Amazon. com to Amazon. love: How Alexa is redefining companionship and interdependence for people with special needs. Psychol. Mark. 2021, 38, 596-609. [CrossRef]

19. Hu, R.; Linner, T.; Trummer, J.; Güttler, J.; Kabouteh, A.; Langosch, K.; Bock, T. Developing a Smart Home Solution Based on Personalized Intelligent Interior Units to Promote Activity and Customized Healthcare for Aging Society. J. Popul. Ageing 2020, 13, 257-280. [CrossRef]

20. Oliveira, L.; Mitchell, V.; May, A. Smart home technology-comparing householder expectations at the point of installation with experiences 1 year later. Pers. Ubiquitous Comput. 2020, 24, 613-626. [CrossRef]

21. Taiwo, O.; Ezugwu, A.E. Internet of Things-Based Intelligent Smart Home Control System. Secur. Commun. Netw. 2021, 2021, 9928254. [CrossRef]

22. Smys, S. A Survey on Internet of Things (IoT) based Smart Systems. J. ISMAC 2020, 2, 181-189. [CrossRef]

23. Georgia, D.; Evangelia, F.; Georgios, C.; Christos, M.; Thomas, K. Evaluation of end user requirements for Smart Home applications and services based on a decision support system. Internet Things 2021, 16, 100431. [CrossRef]

24. Yang, H.; Lee, W.; Lee, H. IoT smart home adoption: The importance of proper level automation. J. Sens. 2018, $2018,6464036$. [CrossRef]

25. Hui, T.K.; Sherratt, R.S.; Sánchez, D.D. Major requirements for building Smart Homes in Smart Cities based on Internet of Things technologies. Future Gener. Comput. Syst. 2017, 76, 358-369. [CrossRef]

26. Alaa, M.; Zaidan, A.A.; Zaidan, B.B.; Talal, M.; Kiah, M.L.M. A review of smart home applications based on Internet of Things. J. Netw. Comput. Appl. 2017, 97, 48-65. [CrossRef]

27. Gram-Hanssen, K.; Darby, S.J. "Home is where the smart is?" Evaluating smart home research and approaches against the concept of home. Energy Res. Soc. Sci. 2018, 37, 94-101. [CrossRef]

28. Tao, M.; Zuo, J.; Liu, Z.; Castiglione, A.; Palmieri, F. Multi-layer cloud architectural model and ontology-based security service framework for IoT-based smart homes. Future Gener. Comput. Syst. 2018, 78, 1040-1051. [CrossRef]

29. O'Dwyer, E.; Pan, I.; Acha, S.; Shah, N. Smart energy systems for sustainable smart cities: Current developments, trends and future directions. Appl. Energy 2019, 237, 581-597. [CrossRef]

30. Rausser, G.; Strielkowski, W.; Štreimikienè, D. Smart meters and household electricity consumption: A case study in Ireland. Energy Environ. 2018, 29, 131-146. [CrossRef]

31. Homod, R.Z. Analysis and optimization of HVAC control systems based on energy and performance considerations for smart buildings. Renew. Energy 2018, 126, 49-64. [CrossRef]

32. Sahari, K.M.; Jalal, M.A.; Homod, R.Z.; Eng, Y.K. Dynamic indoor thermal comfort model identification based on neural computing PMV index. IOP Conf. Ser. Earth Environ. Sci. 2013, 16, 012113. [CrossRef]

33. Lisin, E.; Shuvalova, D.; Volkova, I.; Strielkowski, W. Sustainable development of regional power systems and the consumption of electric energy. Sustainability 2018, 10, 1111. [CrossRef]

34. Statista. Consumer Spending on Smart Home Products and Services Worldwide from 2015 to 2025. Available online: https: //www.statista.com/statistics/693303/smart-home-consumer-spending-worldwide (accessed on 28 September 2021).

35. Sanchez, V.G.; Pfeiffer, C.F.; Skeie, N.O. A review of smart house analysis methods for assisting older people living alone. J. Sens. Actuator Netw. 2017, 6, 11. [CrossRef]

36. Popa, D.; Pop, F.; Serbanescu, C.; Castiglione, A. Deep learning model for home automation and energy reduction in a smart home environment platform. Neural Comput. Appl. 2019, 31, 1317-1337. [CrossRef]

37. Yao, K.C.; Huang, W.T.; Wu, C.C.; Chen, T.Y. Establishing an AI Model on Data Sensing and Prediction for Smart Home Environment Control Based on LabVIEW. Math. Probl. Eng. 2021, 2021, 7572818. [CrossRef]

38. Khattak, H.A.; Farman, H.; Jan, B.; Din, I.U. Toward integrating vehicular clouds with IoT for smart city services. IEEE Netw. 2019, 33, 65-71. [CrossRef]

39. Verma, P.; Sood, S.K. Fog assisted-IoT enabled patient health monitoring in smart homes. IEEE Internet Things J. 2018, 5, 1789-1796. [CrossRef] 
40. Martins, F.; Almeida, M.F.; Calili, R.; Oliveira, A. Design Thinking Applied to Smart Home Projects: A User-Centric and Sustainable Perspective. Sustainability 2020, 12, 10031. [CrossRef]

41. Kim, M.J.; Cho, M.E.; Jun, H.J. Developing design solutions for smart homes through user-centered scenarios. Front. Psychol. 2020, 11, 335. [CrossRef] [PubMed]

42. Oliveira, A.; Calili, R.; Almeida, M.F.; Sousa, M. A systemic and contextual framework to define a country's 2030 agenda from a foresight perspective. Sustainability 2019, 11, 6360. [CrossRef]

43. Sharif, K.; Tenbergen, B. Smart Home Voice Assistants: A Literature Survey of User Privacy and Security Vulnerabilities. Complex Syst. Inform. Model. Q. 2020, 24, 15-30. [CrossRef]

44. Want, R.; Schilit, B.N.; Jenson, S. Enabling the internet of things. Computer 2015, 48, 28-35. [CrossRef]

45. Collotta, M.; Pau, G. Bluetooth for Internet of Things: A fuzzy approach to improve power management in smart homes. Comput. Electr. Eng. 2015, 44, 137-152. [CrossRef]

46. Morton, A.; Reeves, A.; Bull, R.; Preston, S. Empowering and Engaging European building users for energy efficiency. Energy Res. Soc. Sci. 2020, 70, 101772. [CrossRef]

47. Ammi, M.; Alarabi, S.; Benkhelifa, E. Customized blockchain-based architecture for secure smart home for lightweight IoT. Inf. Process. Manag. 2021, 58, 102482. [CrossRef]

48. Mahbub, M. Progressive researches on IoT security: An exhaustive analysis from the perspective of protocols, vulnerabilities, and preemptive architectonics. J. Netw. Comput. Appl. 2020, 168, 102761. [CrossRef]

49. Worighi, I.; Maach, A.; Hafid, A.; Hegazy, O.; Van Mierlo, J. Integrating renewable energy in smart grid system: Architecture, virtualization and analysis. Sustain. Energy Grids Netw. 2019, 18, 100226. [CrossRef]

50. Kumari, A.; Tanwar, S.; Tyagi, S.; Kumar, N.; Obaidat, M.S.; Rodrigues, J.J. Fog computing for smart grid systems in the 5G environment: Challenges and solutions. IEEE Wirel. Commun. 2019, 26, 47-53. [CrossRef]

51. Bari, A.; Jiang, J.; Saad, W.; Jaekel, A. Challenges in the smart grid applications: An overview. Int. J. Distrib. Sens. Netw. 2014, 10, 974682. [CrossRef]

52. Reka, S.S.; Dragicevic, T. Future effectual role of energy delivery: A comprehensive review of Internet of Things and smart grid. Renew. Sustain. Energy Rev. 2018, 91, 90-108. [CrossRef]

53. Tushar, W.; Saha, T.K.; Yuen, C.; Smith, D.; Ashworth, P.; Poor, H.V.; Basnet, S. Challenges and prospects for negawatt trading in light of recent technological developments. Nat. Energy 2020, 5, 834-841. [CrossRef]

54. Sarker, E.; Halder, P.; Seyedmahmoudian, M.; Jamei, E.; Horan, B.; Mekhilef, S.; Stojcevski, A. Progress on the demand side management in smart grid and optimization approaches. Int. J. Energy Res. 2021, 45, 36-64. [CrossRef]

55. Wu, Y.; Zhang, T.; Gao, R.; Wu, C. Portfolio planning of renewable energy with energy storage technologies for different applications from electricity grid. Appl. Energy 2021, 287, 116562. [CrossRef]

56. Van Summeren, L.F.; Wieczorek, A.J.; Bombaerts, G.J.; Verbong, G.P. Community energy meets smart grids: Reviewing goals, structure, and roles in Virtual Power Plants in Ireland, Belgium and the Netherlands. Energy Res. Soc. Sci. 2020, $63,101415$. [CrossRef]

57. Jayachandran, M.; Reddy, C.; Padmanaban, S.; Milyani, A.H. Operational planning steps in smart electric power delivery system. Sci. Rep. 2021, 11, 1-21. [CrossRef]

58. $\mathrm{Wu}, \mathrm{Y}$;; $\mathrm{Wu}, \mathrm{Y}$; Guerrero, J.M.; Vasquez, J.C. Decentralized transactive energy community in edge grid with positive buildings and interactive electric vehicles. Int. J. Electr. Power Energy Syst. 2022, 135, 107510. [CrossRef]

59. Hermeto, R.T.; Gallais, A.; Theoleyre, F. Scheduling for IEEE802. 15.4-TSCH and slow channel hopping MAC in low power industrial wireless networks: A survey. Comput. Commun. 2017, 114, 84-105. [CrossRef]

60. Popham, K. Transportation Electrification. In Smart Cities; Springer: Berlin/Heidelberg, Germany, 2018; pp. 109-122. [CrossRef]

61. Pino, N.; Skinner, C.A. Best Smart Home Devices 2021: Automate Your Home with These Gadgets. Available online: https: //www.techradar.com/news/smart-home-devices (accessed on 8 November 2021).

62. Brown, R.; Priest, D.; Crist, R.; Price, M. Best Smart Home Devices to Buy in 2021. Available online: https://www.cnet.com/ home/smart-home/ best-smart-home-devices (accessed on 8 November 2021).

63. Zheng, X.; Cai, Z.; Li, Y. Data linkage in smart internet of things systems: A consideration from a privacy perspective. IEEE Commun. Mag. 2018, 56, 55-61. [CrossRef]

64. Balitskiy, S.; Bilan, Y.; Strielkowski, W. Energy security and economic growth in the European Union. J. Secur. Sustain. Issues 2014, 4, 125-132. [CrossRef]

65. Nižetić, S.; Šolić, P.; González-de-Artaza, D.L.-D.-I.; Patrono, L. Internet of Things (IoT): Opportunities, issues and challenges towards a smart and sustainable future. J. Clean. Prod. 2020, 274, 122877. [CrossRef] [PubMed]

66. Al-Sarawi, S.; Anbar, M.; Abdullah, R.; Al Hawari, A.B. Internet of Things Market Analysis Forecasts, 2020-2030. In Proceedings of the 2020 Fourth World Conference on Smart Trends in Systems, Security and Sustainability (WorldS4), London, UK, 27-28 July 2020; pp. 449-453. [CrossRef]

67. Chiabai, A.; Platt, S.; Strielkowski, W. Eliciting users' preferences for cultural heritage and tourism-related e-services: A tale of three European cities. Tour. Econ. 2014, 20, 263-277. [CrossRef]

68. Dutot, V.; Bhatiasevi, V.; Bellallahom, N. Applying the technology acceptance model in a three-countries study of smartwatch adoption. J. High Technol. Manag. Res. 2019, 30, 1-14. [CrossRef]

69. Thum, Y.M. Hierarchical linear models for multivariate outcomes. J. Educ. Behav. Stat. 1997, 22, 77-108. [CrossRef] 
70. Reyes, D.M.; de Souza, R.M.; De Oliveira, A.L. A three-stage approach for modeling multiple time series applied to symbolic quartile data. Expert Syst. Appl. 2021, 187, 115884. [CrossRef]

71. Kashintseva, V.; Strielkowski, W.; Streimikis, J.; Veynbender, T. Consumer attitudes towards industrial $\mathrm{CO}_{2} \mathrm{capture}$ and storage products and technologies. Energies 2018, 11, 2787. [CrossRef]

72. Shouran, Z.; Ashari, A.; Priyambodo, T. Internet of things (IoT) of smart home: Privacy and security. Int. J. Comput. Appl. 2019, 182, 3-8. [CrossRef]

73. Yang, H.; Lee, H.; Zo, H. User acceptance of smart home services: An extension of the theory of planned behavior. Ind. Manag. Data Syst. 2017, 117, 68-89. [CrossRef]

74. Marikyan, D.; Papagiannidis, S.; Alamanos, E. A systematic review of the smart home literature: A user perspective. Technol. Forecast. Soc. Chang. 2019, 138, 139-154. [CrossRef]

75. Li, W.; Yigitcanlar, T.; Erol, I.; Liu, A. Motivations, barriers and risks of smart home adoption: From systematic literature review to conceptual framework. Energy Res. Soc. Sci. 2021, 80, 102211. [CrossRef]

76. Iten, R.; Wagner, J.; Zeier Röschmann, A. On the Identification, Evaluation and Treatment of Risks in Smart Homes: A Systematic Literature Review. Risks 2021, 9, 113. [CrossRef]

77. Blythe, J.M.; Johnson, S.D. A systematic review of crime facilitated by the consumer Internet of Things. Secur. J. 2021, 34, 97-125. [CrossRef] 